\title{
What is the appropriate time to measure outcome and process factors in psychodynamic psychotherapy?
}

\author{
Qual o tempo apropriado pata medir fatores de resultado e processo em \\ psicoterapia psicodinâmica?
}

\author{
Camila Piva Da Costa, ${ }^{1}$ (iD Carolina Stopinski Padoan, ${ }^{1}$ \\ Simone Hauck, ${ }^{1}$ Stefania Pigatto Teche, ${ }^{1}$ (D) Cláudio Laks Eizirik ${ }^{1}$
}

\begin{abstract}
Introduction: Different instruments and methods for measuring factors related to the progress and effectiveness of psychodynamic psychotherapy (PDT) have been widely discussed in the literature. However, there are no established guidelines on the most appropriate time to perform these measurements.

Objectives: The aim of this study is to problematize what is the appropriate time to measure the initial outcomes (symptoms, interpersonal relationships, quality, and social role) and process factors (alliance) in the early stages of PDT.

Methods: A naturalistic cohort study was conducted, following 304 patients during the first six months of psychotherapy. The therapeutic alliance was evaluated after four sessions; symptoms, interpersonal relationships, and social role were evaluated at intake and after 12 and 24 sessions.

Results: Our results indicate that four sessions were sufficient to measure the bond dimension of the therapeutic alliance, while more time is probably needed to adequately measure other aspects of the therapeutic alliance, such as tasks and goals. However, 12 sessions of treatment proved sufficient to detect improvements in all dimensions of the outcome instruments with moderate effect sizes, and those gains were stable at the 24th session.

Conclusion: According to our findings, 12 sessions seem to be sufficient to assess initial gains in PDT, although more studies are needed to evaluate the appropriate time to assess all aspects of the therapeutic alliance. Further studies are also required to evaluate the appropriate time to assess intermediate and longterm progress with regard to symptoms, interpersonal relations, social role and personality reorganization.
\end{abstract}

Keywords: Psychodynamic psychotherapy, psychotherapy, cohort studies, interpersonal relations, treatment outcome.

\section{Resumo}

Introdução: Diferentes instrumentos e formas de medir fatores relacionados ao progresso e à efetividade da psicoterapia psicodinâmica (PDT) têm sido amplamente discutidos na literatura. No entanto, não há diretrizes estabelecidas sobre o tempo apropriado para que essas medidas sejam realizadas.

Objetivos: O objetivo deste estudo é problematizar qual o momento apropriado para medir resultados iniciais (sintomas, relações interpessoais e papel social) e fatores de processo (aliança) nos estágios iniciais da PDT.

Métodos: Realizou-se estudo de coorte naturalista que acompanhou 304 pacientes durante os primeiros seis meses de psicoterapia. A aliança terapêutica foi avaliada após quatro sessões; sintomas, relações interpessoais e papel social foram avaliados na entrevista de entrada e após 12 e 24 sessões.

Resultados: Nossos resultados indicam que quatro sessões foram suficientes para medir a dimensão do vínculo da aliança terapêutica, enquanto que é necessário mais tempo para medir adequadamente outros aspectos da aliança terapêutica, como tarefas e objetivos. No entanto, 12 sessões de tratamento revelaram-se suficientes para detectar melhora em todas as dimensões dos instrumentos de resultados com tamanhos de efeito moderados, e esses ganhos se mostraram estáveis na $24 a$ sessão.

Conclusão: De acordo com nossos achados, 12 sessões parecem ser suficientes para acessar os ganhos iniciais na PDT, porém mais estudos são necessários para avaliar o tempo apropriado de medir todos os aspectos da aliança terapêutica. São necessários mais estudos para avaliar o tempo apropriado para avaliar os ganhos intermediários e de longo prazo em relação a sintomas, função interpessoal e função social.

Descritores: Psicoterapia psicodinâmica, psicoterapia, estudos de coorte, relações interpessoais, resultado de tratamento.

\footnotetext{
${ }^{1}$ Hospital de Clínicas de Porto Alegre (HCPA), Universidade Federal do Rio Grande do Sul (UFRGS), Porto Alegre, RS, Brazil. Submitted Dec 23 2017, accepted for publication Aug 082018.

Suggested citation: Da Costa CP, Padoan CS, Hauck S, Teche SP, Eizirik C. What is the appropriate time to measure outcome and process factors in psychodynamic psychotherapy? Trends Psychiatry Psychother. 2019;41(2):112-120. http://dx.doi.org/10.1590/2237-6089-2017-0151
} 


\section{Introduction}

Consistent evidence has been published showing the effectiveness of psychodynamic psychotherapy (PDT) with effect sizes similar to "empirically supported" psychotherapy approaches. ${ }^{1-3}$ PDT aims to go beyond a mere reduction of symptoms and instead furnish patients with a better understanding of the sources of personal, interpersonal, and professional difficulties..$^{4-7}$

Several studies have investigated which factors of the psychotherapy process have an influence on treatment effectiveness and how PDT outcomes can be reliably measured using various instruments. ${ }^{4-9}$ According to Brown, Scholle, and Azur, ${ }^{10}$ measurements taken throughout PDT help identify potential dropouts. Additionally, feedback has a positive effect on treatment outcomes. ${ }^{11}$

However, at present, no thorough guidelines exist with regards to the appropriate time during treatment for measuring each of the process and outcome factors. This issue is very important, considering the importance of defining the appropriate dose of psychotherapy, since this information could be used to define protocols for public health authorities and private insurance companies.

Clinical trials have shown that in carefully controlled and implemented treatments between $57.6 \%$ and $67.2 \%$ of patients improve in an average of 12.7 sessions. Further, research on the dose-effect relationship of psychotherapy has shown that 11 to 21 sessions would be necessary for at least $50 \%$ of patients to recover. ${ }^{12,13}$ Other studies have described a dosage model of psychotherapeutic effectiveness that demonstrates a linear relationship between the number of sessions and the probability of patient improvement (log-normal dose). ${ }^{14}$ Fifty percent of a sample showed reliable improvement by session $6,60 \%$ by session $10,69 \%$ by session 26 , and $74 \%$ by session $52 .{ }^{14}$ However, naturalistic data from a nationwide database of over 6,000 patients revealed that the average patient actually received fewer than five sessions. The rate of improvement in that sample was only about $20 \%$. These results suggest that, on average, patients do not get adequate doses of psychotherapy and that the recovery process is jeopardized as a consequence. ${ }^{13,15}$ Barrett, Chua, Crits-Christoph, Gibbons, and Thompson found that a mere $50 \%$ of patients who scheduled an initial appointment at an outpatient clinic actually attended and, after intake, only $20 \%$ completed more than three sessions. ${ }^{16}$ This illustrates the importance of considering what would be the proper protocol for evaluating PDT results that are relevant to different naturalistic settings.
Establishing the appropriate time for different measures is especially important, considering the complexity of the PDT treatment. PDT seeks to return the patient to a natural path of personal development through the therapist-patient relationship (transference). Constructive revisions in one's sense of self and changes in representations of self and others are fostered through refinement of meta-reflective abilities. ${ }^{4,17}$ As part of the process, the patient may go through a phase during which they become unsettled and symptoms appear to worsen. This is to be expected and may necessarily precede resolution of the internal conflicts that originally drove the patient to seek therapy. The whole process is potentially non-linear and complex, which makes it all the more important to establish the appropriate time at which to evaluate the patient's progress. ${ }^{18}$

Considering models of the stages of psychotherapy, we found the Hill three-phase model. ${ }^{19}$ The first phase is called the approach stage and involves exploration, insight, and action. Exploration is based on patientcentered theory and aims to help patients explore their thoughts and feelings. The next phase is the insight stage, which involves helping patients understand the reasons behind their thoughts and feelings. The final phase, the action stage, focuses on helping patients build the desired changes in their lives.

Another model is based on the concept of "illness," which has three components: feeling ill, showing symptoms, and suffering from a functional disability. ${ }^{14,19}$ This model emphasizes empathy, collaboration with the patient throughout therapy, cultural considerations, and taking into account the needs of the individual patient. The illness model presents a three-phase conception of the healing process, as follows: 1) remoralization, the enhancement of well-being, which is usually accomplished within a few sessions; 2 ) remediation, the attainment of symptomatic relief, which is accomplished more gradually; and 3) rehabilitation, the unlearning of troublesome, maladaptive, long-standing behavior and the establishing of new ways of dealing with various aspects of life, which is the final phase. ${ }^{20,21}$ Given that treatment has these different models and phases, it is relevant to follow the patient's progress through therapy by identifying which phase of therapy they have reached.

Since the international literature identifies 12 sessions as the correct dose of psychotherapy for obtaining early improvement, this could be a suitable juncture at which to evaluate initial outcomes. In terms of process factors, the therapeutic alliance is the most accurate predictor of psychotherapy outcomes, regardless of the type of therapeutic approach. ${ }^{12-14}$ The 
alliance tends to be formed during the initial therapy sessions, and the duration of the assessment period has been put at two to four sessions. ${ }^{21-24}$ However, it is not clear whether psychotherapy-staging aspects were considered in obtaining these results. Hence, the aim of this study was to investigate the hypotheses that the therapeutic alliance (process factor) can be adequately evaluated by four sessions and that therapeutic improvement (outcome factors) can be evaluated at 12 or 24 sessions.

\section{Method}

\section{Setting}

Our longitudinal and naturalistic study was conducted at an outpatient mental health clinic located in Porto Alegre, southern Brazil. The clinic offers PDT to the general population and is integrated into a PDT school that provides a PDT training course. Patients seek the clinic voluntarily and initial evaluation comprises the following procedures: 1) people who seek PDT are screened by psychologists trained to conduct intake interviews specialized in PDT; 2) if PDT is recommended by the interviewer, the patient is referred to a therapist. Patients are assigned therapists based on schedule availability. Treatment is openended, based on the long-term psychodynamic model, and frequency is one session per week.

During the initial interview, patients were invited to participate in the study and given instructions. The clinic's adherence to PDT was the subject of a previous study. ${ }^{25}$

\section{Participants}

The study enrolled 304 adult patients who initiated PDT from April 2015 to May 2016 and 51 therapists who agreed to participate in the study. Most of the patients were women $(66 \%$, vs. $34 \%$ men). With respect to ethnicity, $83 \%$ of patients were white, $10 \%$ were multiracial, and $7 \%$ were black. The mean age was 32.6 years ( \pm 10.3 ), and $77 \%$ had higher education. Personal income was measured in multiples of the minimum wage (MW) and $33 \%$ of participants earned 4 to 6 times the MW, $32 \%$ earned 1 to 3 times the MW, $25 \%$ earned 7 or more times the MW, and $10 \%$ earned less than the MW. Regarding marital status, $63 \%$ were single and $37 \%$ were married. At screening, the main diagnostic hypotheses were mood disorder (40\%) and anxiety disorder $(40 \%)$, followed by adult personality disorders and behavioral disorders (10\%), mental and behavioral disorders due to psychoactive substance use $(5 \%)$, and behavioral syndromes associated with physiological disturbances and physical factors (5\%). The main reasons for seeking therapy were depressive problems $(47 \%)$, anxiety problems (33\%), avoidant personality problems $(10 \%)$, antisocial personality problems $(8 \%)$, and somatic problems $(2 \%)$. Most of the therapists participating in this study were women $(92 \%)$, and their mean age was 34.5 years ( \pm 9.8 ). Regarding academic training, 20 of the therapists $(40 \%)$ had five or more years of PDT experience at the clinic, 15 (31\%) had one year's experience, 8 (16\%) had two years' experience, and 8 (13\%) had three years' experience. Each therapist had an average of $5.67(\mathrm{SD}=3.64)$ patients.

\section{Instruments}

Clinical and sociodemographic questionnaire

Data reported by the patients were collected from a baseline assessment instrument completed by the patients and from notes taken by professionals during the intake interviews.

\section{Symptom Checklist-90-Revised (SCL-90-R)}

This instrument assesses nine dimensions of patient symptomatology: somatization, obsessiveness/ compulsivity, interpersonal sensitivity, depression, anxiety, hostility, phobic anxiety, paranoid ideation, and psychoticism. Scores are provided for the patient's global severity (global severity index, GSI), the number of symptoms reported by the patient from a 90-item inventory (positive symptom total, PST), and the intensity of the symptoms (positive symptom distress index, PSDI). This instrument was developed by Derogatis and Savitz and was adapted and validated for the Brazilian population by Laloni. 26,27

\section{Outcome Questionnaire (OQ-45)}

This instrument was developed to take repeated measures of a patient's progress in psychotherapy. ${ }^{28}$ The questionnaire comprises a 45 -item self-report scale with which patients rate their functioning over the past week on a five-point Likert scale ranging from "never" to "almost always." The OQ-45 can be used to obtain a baseline measure and then a patient's therapeutic progress can be tracked longitudinally across therapy sessions. This instrument was developed to assess three scales: Symptom Distress (symptoms from the most frequently diagnosed mental disorders, heavily loaded with items that measure depression and anxiety and including items for detection of substance abuse); Interpersonal Relations (including items that assess problems with friendships, family life, and marriage, particularly elements of isolation, feelings of inadequacy, withdrawal, and conflict); and Social 
Role (gauging the patient's level of dissatisfaction, conflict, or distress in his/her employment, family roles, and leisure life). The OQ- 45 has been translated and adapted to the context of Brazilian culture on the basis of the original English version and a European Portuguese version. ${ }^{29}$

\section{Working Alliance Inventory - Long version (WAI)}

This inventory assesses the therapeutic alliance in different psychotherapeutic approaches. The WAI was developed by Horvath ${ }^{30}$ and measures the degree of collaboration between therapist and patient in terms of agreement about tasks (specific activities developed by the pair to foster changes), goals (negotiation and agreement on outcome-related therapy goals), and bond (interpersonal relationship between patient and therapist), in accordance with the three aspects of Bordin's alliance model. ${ }^{31}$ In the WAI, respondents (patients and therapists) are asked to rate the extent to which they feel certain statements describing the relationship and collaboration are true on a seven-point Likert scale from 1 (never) to 7 (always). The 36-item version scale used has demonstrated temporal stability and high internal consistency and has been shown to possess good convergent and discriminant validity. The reliable association with psychotherapy outcome has been suggested as an indicator of the WAI's external or criterion validity. ${ }^{32}$

\section{Data collection}

Patient screening at intake interviews included a clinical and sociodemographic questionnaire, the Symptom Checklist-90-Revised (SCL-90-R), and the Outcome Questionnaire (OQ-45). During the interview, patients were invited to participate in the study, received information about all the procedures, and provided informed consent. After the intake interview, patients initiated the psychotherapy. When each patient completed their fourth psychotherapy session, the WAI was administered to both patient and therapist. This time point was identified in previous research as ideal for effective data gathering on working alliance..$^{21,24}$ The SCL-90-R and OQ-45 were administered again after 12 and 24 sessions of treatment, to evaluate therapeutic progress. Patients were assured of their right to be informed about the results of their individual assessment, and therapists were assured that the study database did not identify the therapist. To minimize bias in their responses, patients were asked to return the envelopes to the receptionist instead of returning them to the therapist. The envelopes were then delivered to the research team.

\section{Data analysis}

Data were entered into a Microsoft Excel spreadsheet and then exported to SPSS for statistical analysis. Quantitative variables were summarized using means and standard deviations, while categorical variables were converted into percentages. The therapeutic alliance data were analyzed according to the linear mixed model estimated by restricted maximum likelihood, using SPSS V.21 statistical software. The outcomes analyzed were the therapeutic alliance variables from the WAI instrument as a fixed factor and the following adjustment variables: characteristics of the patient (sex, age, and diagnostic hypothesis) and characteristics of the therapist (gender, age, and length of experience).

To evaluate the OQ-45 and SLC-90-R, hierarchical linear modeling (HLM) was used to analyze variation over time, considering the patient and therapist pair as a subject. The co-variance structure used was Compound Symmetry. The Bonferroni correction was used to correct for multiple comparisons. The significance level was set at $5 \%$. The resulting effect size was established for each measure at all three time points (Cohen's d). Following general convention, ${ }^{33}$ an effect size of 0.20 was considered to be a small effect, 0.40 a moderate effect, and 0.80 a large effect.

\section{Ethical considerations}

The present study was approved by the ethics committee responsible for medical research where the study was conducted (CAAE 43011815.4.0000.5347). All international standards for research involving human subjects were followed. To avoid interference in the therapeutic process, therapists and patients were not involved in the data collection procedures. The patients were informed about their right to withdraw from the study, voluntary participation, and potential risks and benefits. Patients who agreed to participate (signing informed consent after the research goals and methods had been fully explained) comprised the study sample.

\section{Results}

Results are presented starting with the process factor (therapeutic alliance), followed by outcome factors (symptoms, interpersonal relationships, and social role). At baseline (time 1), 304 patients initiated psychotherapy and 289 agreed to participate in the study. After the fourth session, 272 patients completed the therapeutic alliance questionnaires. After 12 sessions (time 2), 144 patients participated, 
and after 24 sessions (time 3), 65 patients participated. The flowchart illustrating participation and attrition is presented below (Figure 1).

\section{Process factor: therapeutic alliance}

With regard to the therapeutic alliance inventory (WAI), there were statistically significant differences between the perceptions of patients and therapists in the tasks $(p=0.001)$ and goals $(p<0.001)$ dimensions and also in total scores $(p=0.002)$. There were no significant differences in the bond dimension $(p=0.184)$ (Table 1). Therefore, at the time of measurement, despite a similar perception of bond, patients and therapists disagreed on what the focus of therapy (goals) should

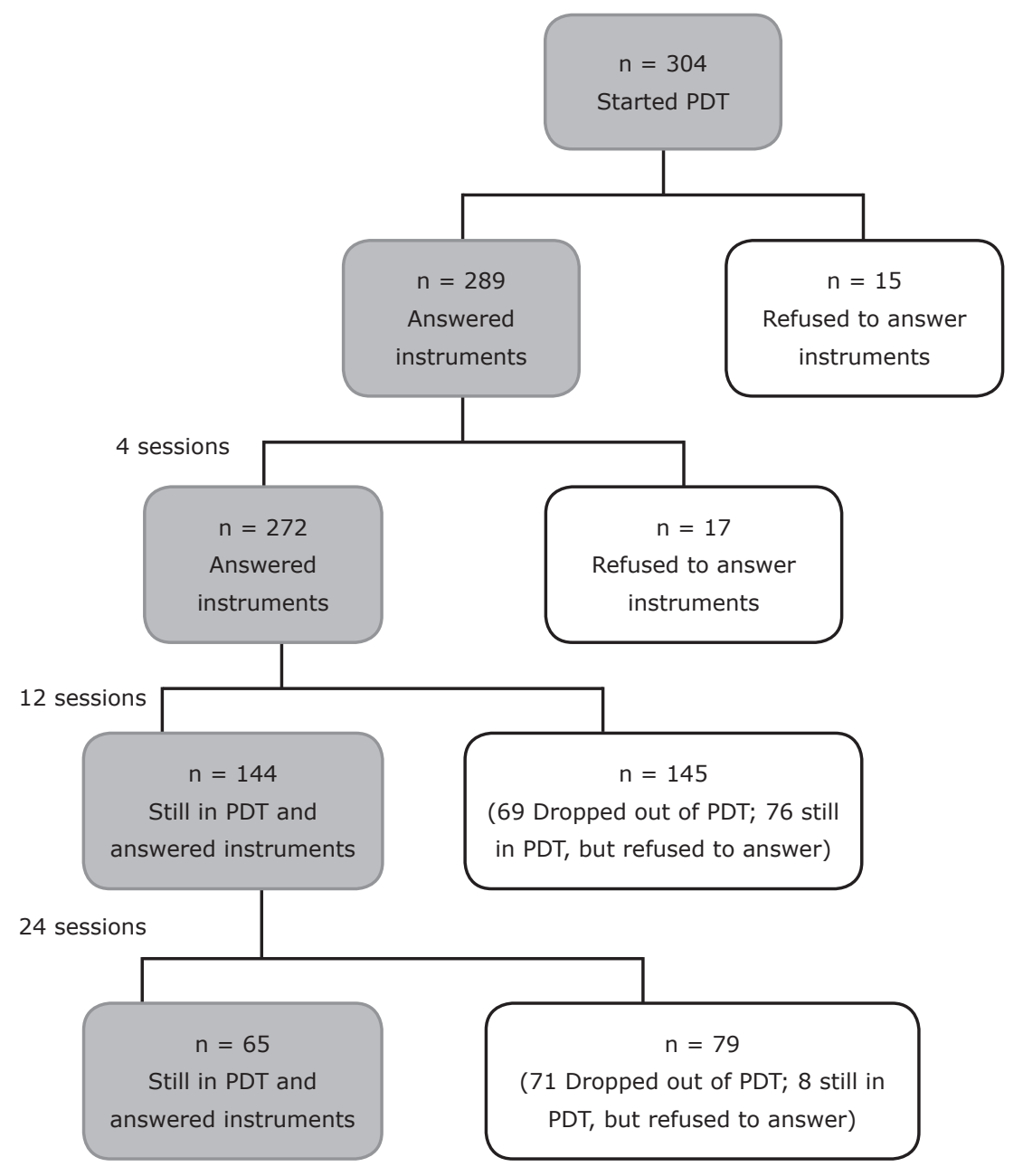

Figure 1 - Flowchart illustrating participation and attrition. PDT = psychodynamic psychotherapy.

Table 1 - Therapeutic alliance between patient and therapist after four sessions

\begin{tabular}{lcccc}
\hline & Patient & Therapist & Difference & p \\
\hline Task & $5.81(5.69-5.93)$ & $5.57(5.48-5.65)$ & $0.25(0.10-0.39)$ & 0.001 \\
Bond & $5.81(5.70-5.91)$ & $5.72(5.64-5.80)$ & $0.08(-0.04-0.21)$ & 0.184 \\
Goal & $5.56(5.44-5.68)$ & $5.26(5.16-5.35)$ & $0.31(0.16-0.45)$ & $<0.001$ \\
Total & $5.73(5.62-5.83)$ & $5.51(5.43-5.59)$ & $0.21(0.08-0.34)$ & 0.002 \\
\hline
\end{tabular}

Data expressed as mean ( $95 \%$ confidence interval).

Means compared by linear model analyses. 
be and on what should be done to achieve treatment goals (tasks). Patients tended to rate the therapeutic alliance higher than therapists (total score).

\section{Outcome factors: symptoms and treatment progress}

Table 2 shows a comparison of the OQ-45 subscales at three time points (pre-treatment/screening, after 12 treatment sessions, and after 24 treatment sessions). There were statistically significant differences in the overall score between time points 1 and 2, and the effect size was moderate. An improvement in symptoms was observed from pre-treatment to 12 sessions of treatment and was maintained after 24 sessions of treatment. There was no additional improvement from 12 sessions to 24 sessions.

Table 3 shows a comparison of SCL-90-R dimensions at the three time points. There were statistically significant differences between time points 1 and 2 for most dimensions and the effect size was moderate. There was a decrease in symptoms from pre-treatment to 12 sessions of treatment, and this improvement was maintained at 24 sessions of treatment. There was no additional improvement from 12 sessions to 24 sessions. The only dimension that evolved differently from this pattern was phobic anxiety, for which there was a statistically significant difference only between time points 1 and $3(p=0.003, d=0.33(0.06-0.60)$, indicating that this symptom took more time to improve in our sample (24 sessions of treatment).

\section{Discussion}

Although interpreting these data is difficult because of the complexity of the psychodynamic process, discussion about the most appropriate time to assess the constructs of therapeutic alliance and initial outcome is crucial to development of research protocols capable of evaluating what we wish to measure. PDT involves several subjective variables, including not only the characteristics of patients and

Table 2 - Comparison of OQ-45 subscales at three time points.

\begin{tabular}{|c|c|c|c|c|c|c|c|c|c|c|c|c|}
\hline \multirow[b]{2}{*}{ OQ-45 subscales } & \multicolumn{2}{|c|}{ Time point 1} & \multicolumn{2}{|c|}{ Time point 2} & \multicolumn{2}{|c|}{ Time point 3} & \multirow[b]{2}{*}{$p(1-2)$} & \multirow{2}{*}{$\begin{array}{c}\text { Effect size } \\
(95 \% \mathrm{CI})\end{array}$} & \multirow[b]{2}{*}{$p(1-3)$} & \multirow{2}{*}{$\begin{array}{c}\text { Effect size } \\
(95 \% \mathrm{CI})\end{array}$} & \multirow[b]{2}{*}{$p(2-3)$} & \multirow{2}{*}{$\begin{array}{c}\text { Effect size } \\
(95 \% \mathrm{CI})\end{array}$} \\
\hline & Mean & SD & Mean & SD & Mean & SD & & & & & & \\
\hline Symptom distress & 45.89 & 15.35 & 35.28 & 16.13 & 34.71 & 12.66 & $<0.001$ & $0.68(0.47-0.88)$ & $<0.001$ & $0.75(0.47-1.02)$ & 0.999 & $0.04(-0.26-0.33)$ \\
\hline $\begin{array}{l}\text { Interpersonal } \\
\text { relations }\end{array}$ & 18.76 & 6.16 & 16.83 & 7.82 & 16.68 & 6.33 & 0.001 & $0.3(0.08-0.49)$ & 0.001 & $0.34(0.07-0.61)$ & 0.999 & $0.02(-0.27-0.31)$ \\
\hline Social role & 14.11 & 5.23 & 12.07 & 4.39 & 12.14 & 3.94 & $<0.001$ & $0.41(0.21-0.61)$ & $<0.001$ & $0.40(0.12-0.66)$ & 0.999 & $0.01(-0.31-0.28)$ \\
\hline Total score & 78.12 & 23.72 & 64.21 & 24.82 & 63.51 & 20.22 & $<0.001$ & $0.58(0.37-0.78)$ & $<0.001$ & $0.63(0.36-0.90)$ & 0.886 & $0.03(-0.26-0.32)$ \\
\hline
\end{tabular}

$95 \% \mathrm{CI}=95 \%$ confidence interval; OQ-45 = Outcome Questionnaire; SD = standard deviation.

p-values were obtained using a hierarchical linear modeling analysis. Effect size by Cohen's d.

Table 3 - Comparison of SCL-90-R dimensions at three time points

\begin{tabular}{|c|c|c|c|c|c|c|c|c|c|c|c|c|}
\hline \multirow{2}{*}{$\begin{array}{l}\text { SCL-90-R } \\
\text { subscales }\end{array}$} & \multicolumn{2}{|c|}{ Time point 1} & \multicolumn{2}{|c|}{ Time point 2} & \multicolumn{2}{|c|}{ Time point 3} & \multirow[b]{2}{*}{$p(1-2)$} & \multirow{2}{*}{$\begin{array}{c}\text { Effect size } \\
(95 \% \mathrm{CI})\end{array}$} & \multirow[b]{2}{*}{$p(1-3)$} & \multirow{2}{*}{$\begin{array}{c}\text { Effect size } \\
(95 \% \mathrm{CI})\end{array}$} & \multirow[b]{2}{*}{$p(2-3)$} & \multirow{2}{*}{$\begin{array}{c}\text { Effect size } \\
(95 \% \mathrm{CI})\end{array}$} \\
\hline & Mean & SD & Mean & SD & Mean & SD & & & & & & \\
\hline $\begin{array}{l}\text { Global Severity } \\
\text { Index }\end{array}$ & 1.3 & 0.7 & 0.96 & 0.66 & 0.87 & 0.58 & $<0.001$ & $0.5(0.29-0.70)$ & $<0.001$ & $0.62(0.35-0.89)$ & 0.129 & $0.14(-0.16-0.43)$ \\
\hline $\begin{array}{l}\text { Positive Symptom } \\
\text { Total }\end{array}$ & 52.41 & 19.57 & 46.4 & 21.92 & 45.05 & 19.3 & 0.001 & $0.3(0.09-0.50)$ & 0.001 & $0.38(0.11-0.65)$ & 0.343 & $\begin{array}{c}0.06(-0.23- \\
0.360\end{array}$ \\
\hline $\begin{array}{l}\text { Positive Symptom } \\
\text { Distress Index }\end{array}$ & 2.07 & 0.59 & 1.69 & 0.54 & 1.63 & 0.49 & $<0.001$ & $0.66(0.46-0.87)$ & $<0.001$ & $0.77(0.49-1.04)$ & 0.541 & $0.11(-0.18-0.41)$ \\
\hline Somatization & 1.14 & 0.92 & 0.86 & 0.75 & 0.83 & 0.72 & $<0.001$ & $0.32(0.12-0.52)$ & 0.001 & $0.35(0.08-0.62)$ & 0.999 & $0.04(-0.25-0.33)$ \\
\hline $\begin{array}{l}\text { Obsessiveness/ } \\
\text { compulsivity }\end{array}$ & 1.46 & 0.83 & 1.15 & 0.83 & 1.03 & 0.69 & $<0.001$ & $0.37(0.17-0.57)$ & $<0.001$ & $0.53(0.26-0.80)$ & 0.102 & $0.15(-0.14-0.45)$ \\
\hline $\begin{array}{l}\text { Interpersonal } \\
\text { sensitivity }\end{array}$ & 1.54 & 0.89 & 1.2 & 0.84 & 1.07 & 0.86 & $<0.001$ & $0.4(0.19-0.59)$ & $<0.001$ & $0.53(0.26-0.80)$ & 0.083 & $0.15(0.14-0.45)$ \\
\hline Depression & 1.82 & 0.91 & 1.32 & 0.88 & 1.23 & 0.75 & $<0.001$ & $0.56(0.35-0.76)$ & $<0.001$ & $0.67(0.39-0.94)$ & 0.307 & $0.11(-0.19-0.40)$ \\
\hline Anxiety & 1.21 & 0.9 & 0.85 & 0.81 & 0.77 & 0.64 & $<0.001$ & $0.41(0.21-0.61)$ & $<0.001$ & $0.51(0.24-0.78)$ & 0.660 & $0.1(-0.19-0.40)$ \\
\hline Hostility & 1.15 & 0.96 & 0.69 & 0.67 & 0.7 & 0.68 & $<0.001$ & $0.53(0.32-0.73)$ & $<0.001$ & $0.5(0.22-0.76)$ & 0.999 & $0.01(-0.31-0.28)$ \\
\hline Phobic anxiety & 0.71 & 0.84 & 0.57 & 0.69 & 0.45 & 0.53 & 0.057 & $0.18(-0.02-0.38)$ & $<0.003$ & $0.33(0.06-0.60)$ & 0.338 & $0.19(-0.11-0.48)$ \\
\hline Paranoid ideation & 1.2 & 0.89 & 0.88 & 0.74 & 0.86 & 0.78 & $<0.001$ & $0.38(0.18-0.58)$ & 0.001 & $0.38(0.10-0.64)$ & 0.999 & $0(-0.29-0.29)$ \\
\hline Psychoticism & 0.94 & 0.73 & 0.65 & 0.67 & 0.57 & 0.59 & $<0.001$ & $0.41(0.21-0.61)$ & $<0.001$ & $0.52(0.25-0.79)$ & 0.253 & $0.12(-0.17-0.42)$ \\
\hline
\end{tabular}

95\%CI = 95\% confidence interval; SCL-90-R = Symptom Checklist-90-Revised; SD = standard deviation.

p-values were obtained using a hierarchical linear modeling analysis. Effect size by Cohen's d. 
therapists but also phenomena involving the pair in a process that by definition is not necessarily linear. ${ }^{34-}$ 36 It is essential to know the minimum time required to evaluate different outcomes to establish adequate protocols for treatments in different settings, an issue that is particularly relevant for public health authorities and private insurance providers.

In the alliance assessment, patients gave better evaluations than therapists on the goals dimension (negotiation and agreement on therapy goals in terms of outcomes) and on the task dimensions (specific activities developed by the pair to foster changes), while there was no significant difference on the bond dimension (interpersonal relations between patient and therapist). These results may be an indication that therapists prioritize development of the analytical relationship (bond) in the early sessions before establishing goals and tasks and that the bond is established sooner than more "complex" aspects of the therapeutic alliance. 17,37,38 This explanation is consistent with these findings, which identified a difference in treatment goals between patients and therapists at the beginning of PDT.

Nevertheless, despite a difference in evaluation, both patients and therapists gave a positive evaluation of the therapeutic alliance in this study. This finding supports the idea that the difference in treatment goals and tasks may not be a negative factor but may be a stage in an unfinished process, suggesting that more than four sessions would be necessary in order for all aspects of the alliance to be developed. A study of patients' motivation and its association with psychopathological states and session outcomes found that assessing goals in an intermediate phase, between the seventh and the fifteenth session, resulted in more positive evaluations by both patients and therapists than assessments carried out after the first five sessions. ${ }^{39}$

Our findings did not confirm our hypothesis that four sessions would be sufficient for the patient to evaluate process factors such as therapeutic alliance. In Hill's three-phase model, for example, the initial stage of therapy is characterized by patients feeling hopeful about therapy, since they have initiated the help-seeking behaviors (the re-moralization stage). ${ }^{19}$ The therapist should help the patient understand how the analytical work functions, developing a therapeutic bond and identifying complaints more accurately, so that these complaints are turned into psychotherapy goals and tasks. ${ }^{40} \mathrm{We}$, therefore, believe that at four sessions, goals and tasks were being developed, but had not been finalized. Longer periods of psychotherapy are needed to better measure those aspects.

Regarding the outcome measures, this study demonstrated that patients had significantly improved in all OQ-45 subscales and SCL-90-R dimensions at 12 sessions of PDT. They exhibited not only decreases in symptoms, but also improvements in the OQ-45 subscales symptom distress, interpersonal relations, and social role. The dimension that only reduced after 24 sessions was phobic anxiety, which is a persistent fear-related response directed at a person, a place, an object, or a situation. It is irrational and disproportional to stimuli, leading to escape and avoidance behaviors. ${ }^{26}$ Because this is a symptom related to avoidance, the phobic anxiety patient may have more trouble developing a therapeutic bond and may therefore need more time to achieve satisfactory results. Nevertheless, since most of the instruments' subscales and dimensions showed significant improvements after 12 sessions of treatment, these data indicate that this time point may be appropriate for an initial assessment of improvement.

In light of these results, the authors suggest that psychotherapy should be quantified in three stages: early, intermediate, and advanced. This study shows that improvement in symptom distress and other significant factors such as interpersonal relations and social role occurs in the early stage with a 12-session dose.

There is no improvement, however, between 12 and 24 sessions. This period may represent the intermediate phase of psychotherapy, where the patient's defenses are broken down and transference is established. In the advanced phase, personality reorganization occurs, which is part of a specific psychodynamic model that takes even more time. Our hypothesis is that there is no improvement during this period because treatment shifts stages and focuses on structural changes that require more time to produce results.

Further studies are, therefore, needed to determine what time periods are sufficient to measure intermediate and long-term improvement in PDT. 41,42 The authors believe that the effectiveness of PDT depends on a combination of the number of sessions, presence of therapeutic bond, and proper definition of treatment goals and interventions. The authors suggest that the early stage of PDT should comprise 12 sessions and last approximately three months, focusing on crisis symptoms and development of the therapeutic alliance. After this period, all dimensions of the therapeutic alliance, especially the focus of the treatment, should be reassessed when progressing to the intermediate phase. ${ }^{43}$

There are limitations to this study that should be considered. The study was conducted at a single institution. Measurements were only performed during the first 24 sessions of psychotherapy and, as with 
most naturalistic studies; there was a high rate of sample attrition. Measurements of alliance were not repeated at 12 and 24 sessions of treatment. Future research should explore whether changes in alliance and agreement occur at those intervals. The findings would represent an important step toward establishing the appropriate time at which to measure processspecific factors.

Nevertheless, our study raises important questions about the time necessary for measuring different aspects of the therapeutic alliance, a factor that has been proven to be directly associated with the outcome. Our study shows that 12 sessions could be an appropriate point at which to measure several outcome factors in naturalistic PDT settings. This could be relevant not just for the design of research protocols but also in discussions about sufficient doses of psychotherapy in different settings. Our findings could also be useful in instructional settings, such as at the PDT school where our study was conducted, since 12 sessions may be the most appropriate time at which to assess the performance of therapists undergoing PDT training.

\section{Acknowledgements}

This work was supported by Coordenação de Aperfeiçoamento de Pessoal de Nível Superior (CAPES).

\section{Disclosure}

No conflicts of interest declared concerning the publication of this article.

\section{References}

1. Steinert C, Muder T, Rabung S, Hoyer J, Leichsenring F. Psychodynamic therapy: as efficacious as other empirically supported treatments? A meta-analysis testing equivalence of outcomes. Am J Psychiatry. 2017;15:1-11.

2. Fonagy $P$. The effectiveness of psychodynamic psychotherapies: an update. World Psychiatry. 2015;14:137-50.

3. De Maat S, de Jonghe F, de Kraker R, Leichsenring F, Abbass A, Luyten $P$, et al. The current state of the empirical evidence for psychoanalysis: a meta-analytic approach. Harv Rev Psychiatry. 2013;21:107-37.

4. Luyten P, Blatt S, Mayes L. Process and outcome in psychoanalytic psychotherapy research: the need for a (relatively) new paradigm. In: Levy RA, Ablon J, Kachele $\mathrm{H}$, editors. Psychodynamic psychotherapy research: evidence-based practice and practicebased evidence. New York: Humana Press; 2012. p. 145-60.

5. Roth A, Fonagy P. What works for whom: A critical review of psychotherapy research. 2nd ed. London: Guildford; 2005.

6. Shedler J. The efficacy of psychodynamic psychotherapy. Am Psychol. 2010;65:98-109.
7. Leuzinger-Bohleber $M$, Kächele $H$. An open door review of outcome and process studies in psychoanalysis. 3rd ed. London: International Psychoanalytical Association; 2015.

8. Goldfried M. Consensus in psychotherapy research and practice: Where have all the findings gone? Psychother Res. 2000;10:116.

9. Werbart A, Andersson H, Sandell R. Dropout revisited: Patient and therapist initiated discontinuation of psychotherapy as a function. Psychother Res. 2014:24:724-37.

10. Brown J, Scholle SH, Azur M. Strategies for measuring the quality of psychotherapy: A white paper to inform measure development and implementation. Report submitted to the Assistant Secretary for Planning and Evaluation, U.S. Department of Health and Human Services. (Contract No.: HHSP23320095642WC and task order number HHSP 23320100019WI). Washington: Mathematica Policy Research; 2014.

11. Lambert MJ, Harmon C, Slade K., Whipple JL, Hawkins EJ. Providing feedback to psychotherapists on their patient's progress: clinical results and practice suggestions. J Clin Psychol. 2005;61:16574.

12. Hansen NB, Lambert MJ, Forman EM. The psychotherapy doseresponse effect and its implications for treatment delivery services. Clin Psychol. 2002;9:329-43.

13. Lambert MJ. Presidential address: What we have learned from a decade of research aimed at improving psychotherapy outcome in routine care. Psychother Res. 2007;17:1-14.

14. Howard KI, Kopta I, Krause SM, Orlinsky, DE. The dose-response relationship in psychotherapy. Am Psychol. 1986:41:159-64.

15. Schiepek G, Aichhorn W, Gruber M, Strunk G, Bachler E, Aas $B$, et al. Real-time monitoring of psychotherapeutic processes: Concept and compliance. Front Psychol. 2016;7:604.

16. Barrett MS, Chua WJ, Crits-Christoph P, Gibbons MB, Thompson D. Early withdrawal from mental health treatment: Implications for psychotherapy practice. Psychother Theor Res Pract Train. 2008; 45:247-67.

17. Gelso CJ. The real relationship in psychotherapy. The hidden foundation of change. Washington: American Psychological Association; 2011.

18. Grande T, Wolfram K, Rudolf G. What happens after treatment: Can structural change be a predictor of long-term outcome? In: Levy RA, Ablon JS, Kachele $\mathrm{H}$, editors. Psychodynamic psychotherapy research: Evidence-based practice and practicebased evidence. New York: Humana Press; 2012. p. 169-83.

19. Hill CE. Therapist techniques, client involvement, and the therapeutic relationship: Inextricably intertwined in the therapy process. Psychother Theor Res Pract Train. 2005;42:431-42.

20. Howard KI, Lueger RJ, Kolden GG. Measuring progress and outcome in the treatment of affective disorders. In: Horowitz LM, Lambert MJ, Strupp HH, editors. Measuring patient change after treatment for mood, anxiety, and personality disorders: Toward a core battery. Washington: American Psychological Association; 1997. p. 263-81.

21. Norcross JC, Lambert MJ. Psychotherapy relationships that work II. Psychotherapy (Chic). 2011;48:4-8

22. Horvath AO, Del Re AC, Flückiger $C$, Symonds D. Alliance in individual psychotherapy. Psychotherapy (Chic). 2011;48:9-16.

23. Horvath AO. The therapeutic relationship: from transference to alliance. J Clin Psychol. 2000;56:163-73.

24. Philips $B$, Wennberg $P$, Wezbart A. Ideas of cure as a predictor of prematuretermination, earlyallianceand outcomein psychoanalytic psychotherapy. Psychol Psychother. 2007;80:229-45.

25. Gastaud MB, Costa CP, da Padoan CS, Berger D, D'Incao DB, Krieger DV et al. Aderência à técnica na psicoterapia psicanalítica: estudo preliminar. J Bras Psiquiatr. 2012;61:189-90.

26. Derogatis LR, Savitz KL. The SCL-90-R and the Brief Symptom Inventory (BSI) in primary care. In: Maruish ME, editor. Handbook of psychological assessment in primary care settings. Mahwah: Lawrence Erlbaum Associates; 2000. p. 297-334.

27. Laloni D. Escala de Avaliação de Sintomas 90-R (SCL-90-R): Adaptação, precisão e validade [doctoral dissertation]. Campinas: Pontifícia Universidade Católica of Campinas; 2001.

28. Lambert $M$, Burlingame $G$, Umphress V, Hansen N, Vermeersch $D$, Clouse G, et al. The Reliability and Validity of the Outcome Questionnaire. Clin Psychol Psychother. 1996;3:249-58.

29. Carvalho LF, Rocha GMA. Tradução e adaptação cultural do Outcome Questionnaire (OQ-45) para O Brasil. Psico-USF. 2009; 14:309-16.

30. Horvath $A O$, Greenberg, LS. Development and validation of the Working Alliance Inventory. J Couns Psychol. 1989;3:223-33. 
31. Bordin E. The generalizability of the psychoanalytic concept of the working alliance. Psychotherapy (Chic). 1979;16:252-60.

32. Horvath AO. Empirical validation of Bordin's pantheoretical model of alliance: The Working Alliance Inventory perspective. In: Horvath AO, Greenberg LS, editors. The working alliance: theory, research and practice. New York: John Wiley \& Sons; 1994. p. 109-28.

33. Cohen J. Statistical power analysis for the behavioral sciences. 2nd ed. Hillsdale: Lawrence Erlbaum Associates; 1988.

34. Tryon GS, Winograd G. Goal consensus and collaboration. Psychotherapy (Chic). 2011;48:50-7.

35. Daniels J, Wearden AJ. Socialization to the model: The active component in the therapeutic alliance? A preliminary study. Behav Cogn Psychother. 2011;39:221-7.

36. Heinonen E, Lindfors O, Laaksonen MA, Knekt P. Therapists' professional and personal characteristics as predictors of outcome in short- and long-term psychotherapy. J Affect Disord. 2012;138:301-12.

37. Garcia JA, Weisz JR. When youth mental health care stops: Therapeutic relationship problems and other reasons for ending youth outpatienttreatment. JConsultClin Psychol. 2002; 70:439-43.

38. Borgeat F, O'Connor K, Amado D, St-Pierre-Delorme MË. Psychotherapy augmentation through preconscious priming. Front Psychiatry. 2013;4:1-8.
39. Michalak J, Klappheck MA, Kosfelder J. Personal goals of psychotherapy patients: The intensity and the "why" of goalmotivated behavior and their implications for the therapeutic process. Psychother Res. 2004;14:193-209.

40. Schöttke H, Trame L, Sembill A. Relevance of therapy goals in outpatient cognitive-behavioral and psychodynamic psychotherapy. Psychother Res. 2014;24:711-23.

41. Gabbard GO. Long-term psychodynamic psychotherapy: a basic text. Arlington: American Psychiatric Publishing; 2017.

42. Fonagy $P$, Rost $F$, Carlyle JA, McPherson S, Thomas R, Pasco Fearon RM, et al. Pragmatic randomized controlled trial of longterm psychoanalytic psychotherapy for treatment-resistant depression: the Tavistock Adult Depression Study (TADS). World Psychiatry. 2015;14;312-21.

43. Lingiardi V, Colli A, Gentile D, Tanzilli A. Exploration of session process: Relationship to depth and alliance. Psychotherapy. 2011;48:391-400.

\section{Correspondence:}

Camila Piva da Costa

Rua Felix da Cunha, 737/606

90570-001 - Porto Alegre - Brazil

E-mail: camilapdacosta@gmail.com 